\title{
Fat Patterning of Adolescents: Allometry of Fatfolds
}

\author{
M. DANIEL BECQUE, KOMET HATTORI, VICTOR L. KATCH, AND \\ ALBERT P. ROCCHINI \\ Behnke Laboratory for Body Composition Research, Deportment of \\ Movement Science, Division of Kinesiology, and Section of Pediatric \\ Cardiology, Department of Pediatrics, School of Medicine, The \\ University of Michigan, Ann Arbor, Michigan 48109-2214
}

\begin{abstract}
The relationship between fatfold thickness and fat mass of 101 male and 66 female adolescents $(10-16 \mathrm{yr})$ was examined with the allometric equation $y=b^{a}$. Body composition was assessed by underwater weighing and 5 fatfolds were measured: triceps, subscapular, suprailiac, abdominal, and thigh. Percent body fat ranged from $4.9 \%$ to $56.1 \%$. The log of each fatfold thickness was plotted versus the log of fat mass. All the relationships were linear and exhibited monophasic allometry. All the alpha coefficients (slope of the log-log plots) exhibited positive allometry. The prepubescent male and female alphas were similar and had the same pattern. The pattern contrasted the trunk with the extremity fatfolds. No differences $(P>.05)$ were found between the alphas for the pubescent males. The triceps alpha of the pubescent females was less $(P<.05)$ than the subscapular, suprailiac, and abdominal alphas. The thigh, subscapular, suprailiac, and abdominal alphas were not significantly $(P>.05)$ different. In conclusion, the trunk was the predominant site of subcutaneous fat deposition for prepubescents, while pubescents exhibit a more general pattern of fat distribution.
\end{abstract}

1992 Wiley-Liss, Inc.

Subcutaneous fat patterning is affected by gender (Ashwell et al., 1978, 1982), age (Robson et al., 1971; Deutsch et al., 1985), maturation (Frisancho and Flegal, 1982) and adiposity (Garn and Harper, 1955; Forbes and Amirhakimi, 1970; Hattori et al., 1987). It also has been implicated in the etiology of diabetes and coronary artery disease in adults (Bjorntorp, 1985), but surprisingly, not in obese adolescents (Becque et al., 1986).

In a previous paper, we employed multivariate analyses to examine the relationship between adiposity and subcutaneous fat patterning of adolescents (Hattori et al., 1987). We found that the trunk-extremity and upper-lower trunk components explained $80 \%$ of the variance in fat distribution. Furthermore, obese adolescents demonstrated increased trunk fat patterning compared to non-obese adolescents; obese males deposited fat in the lower trunk and obese females deposited fat in the upper trunk.

While multivariate analysis describes the relative patterning of subcutaneous fat
(Mueller and Wollheb, 1981), it does not address the relationship between absolute fatfold thickness and total body fat. Therefore, the purpose of this study was to examine the relationship between fatfold thickness and total body fat and the fat distribution pattern of adolescents.

\section{MATERIALS AND METHODS}

The subjects were 1.01 males and $66 \mathrm{fe}$ males ranging in age from 10 to 16 years (Table 1). The adiposity of the subjects varied from lean to obese. Most of the obese adolescents were participants in a multidimensional study of adolescent obesity at the University of Michigan $(n=36)$; the other

Received July 9, 1991; accepted February 8, 1992.

M. Daniel Becque, Ph.D., is now at Southern Illinois University, Department of Physical Education, Carbondale, IL 62901.

K. Hattori is now at the Laboratory of Anatomy and Physical Fitness, Ibaraki University; Mito, Ibaraki, Japan 310. 
TABLE 1. Descriptive characteristics (Mean $\pm S E M)^{1}$

\begin{tabular}{|c|c|c|c|c|}
\hline & \multicolumn{2}{|c|}{ Males } & \multicolumn{2}{|c|}{ Females } \\
\hline & $\begin{array}{c}\text { Prepubescent } \\
(\mathrm{n}=66)\end{array}$ & $\begin{array}{l}\text { Pubescent } \\
(\mathrm{n}=35)\end{array}$ & $\begin{array}{c}\text { Prepubescent } \\
(\mathbf{n}=35)\end{array}$ & $\begin{array}{c}\text { Pubescent } \\
(\mathrm{n}=31)\end{array}$ \\
\hline Height (cm) & $149.6 \pm 1.10^{\mathrm{a}}$ & $166.5 \pm 1.47^{c}$ & $150.8 \pm 1.40^{\mathrm{a}}$ & $158.6 \pm 1.15^{\mathrm{b}}$ \\
\hline Mass (kg) & $43.2+1.33^{a}$ & $61.3 \pm 1.73^{\mathrm{b}}$ & $46.9 \pm 1.94^{\mathrm{a}}$ & $54.7 \pm 2.14^{\mathrm{b}}$ \\
\hline Age (yr) & $11.6+0.13^{\mathrm{a}}$ & $14.4 \pm 0.19^{b}$ & $11.6 \pm 0.21^{\mathrm{a}}$ & $13.6 \pm 0.28^{\mathrm{b}}$ \\
\hline Fat percent & $26.0 \pm 0.99^{\mathrm{b}}$ & $20.3 \pm 1.85^{\mathrm{a}}$ & $31.7 \pm 1.57^{\mathrm{c}}$ & $27.2+1.61^{\mathrm{bc}}$ \\
\hline Fat mass $(\mathrm{kg})$ & $11.8+0.79^{a}$ & $13.1 \pm 1.53^{\mathrm{a}}$ & $15.5 \pm 1.30^{\mathrm{a}}$ & $15.7 \pm 1.61^{\mathrm{a}}$ \\
\hline Fat free mass $(\mathrm{kg})$ & $31.4 \pm 0.71^{a}$ & $48.2 \pm 1.26^{\mathrm{c}}$ & $31.5 \pm 1.02^{\mathrm{a}}$ & $39.0 \pm 0.94^{\mathrm{b}}$ \\
\hline Triceps fatfold (mm) & $14.6 \pm 0.98^{a}$ & $13.6 \pm 1.76^{\mathrm{a}}$ & $18.8 \pm 1.49^{\mathrm{a}}$ & $18.3 \pm 1.79^{a}$ \\
\hline Subscapular fatfold (mm) & $11.1 \pm 1.20^{\mathrm{a}}$ & $12.1 \pm 2.00^{\mathrm{a}}$ & $15.8 \pm 2.08^{\mathrm{a}}$ & $14.9 \pm 2.32^{\mathrm{a}}$ \\
\hline Suprailiac fatfold (mm) & $15.7 \pm 1.58^{a}$ & $16.3 \pm 2.36^{\mathrm{a}}$ & $18.3+2.17^{\mathrm{a}}$ & $18.5 \pm 2.55^{\mathrm{a}}$ \\
\hline Abdominal fatfold (mm) & $14.9 \pm 1.58^{\mathrm{a}}$ & $16.1 \pm 2.28^{\mathrm{a}}$ & $19.7 \pm 2.35^{\mathrm{a}}$ & $17.7 \pm 2.55^{\mathrm{a}}$ \\
\hline Thigh fatfold (mm) & $19.0 \pm 1.33^{\mathrm{ab}}$ & $16.2 \pm 2.25^{\mathrm{a}}$ & $24.2 \pm 2.05^{b}$ & $23.8 \pm 2.38^{\mathrm{ab}}$ \\
\hline
\end{tabular}

${ }^{1}$ Groups with the same letters are not significantly different $(P>05)$.

data were collected at the University of Illinois at Urbana-Champaign $(n=131)$.

Five fatfolds were measured on the right side of the body: triceps, subscapular, suprailiac, abdominal, and thigh (Behnke and Wilmore, 1974). The test-retest reliability of all fatfold measurements was high and ranged from $r=.90$ to $r=.98$. Body mass (BM) was measured on a Homms beam balance. Body volume (BV) was determined by hydrostatic weighing at residual lung volume with the methods of Katch (1969) and Akers and Buskirk (1969) at Michigan and Illinois, respectively. These two methods give comparable results (Boileau et al., 1981). Body density (BM/BV) was converted to percentage body fat with the Siri (1961) equation. The maturational level of the subjects was rated according to changes in pubic hair (Tanner, 1962).

The allometric equation $\left(y=b x^{a}\right)$ was employed to describe the relationship between total fat mass $(\mathrm{x})$ and each fatfold thickness (y). The allometric equation was transformed into base 10 logarithms,

$$
\log y=a \log x+\log b
$$

In the equation, a (alpha) is the allometric coefficient and $\log b$ is the intercept (Huxley and Tessier, 1936). Alpha is the ratio of the change in $\log \mathrm{x}$ to the corresponding change in $\log \mathrm{y}$. When alpha is 1.00 , the slope of the line is $45^{\circ}$ and the specific changes of $x$ and $y$ are equal. Moreover, when the relationship between a one-dimensional (fatfolds) and a three-dimensional (fat mass) measurement is examined the isometric coefficient is 0.33 .
When alpha is less than 0.33 the specific rate of change in $x$ is greater than the specific rate of change in $y$. This is known as negative allometry. Positive allometry occurs when the specific rate of change in $y$ is greater than the specific rate of change in $x$. Standard allometric methods of analysis were utilized in the present study (Scholl, 1950).

To determine the effects of maturation on the allometric relationship of fatfold thickness to fat mass, subjects were categorized into 2 groups: pre- and early-pubescent (pubic hair stages 1 and 2) and pubescent (stage 3 ). For the sake of simplicity, the former are referred to as prepubescent throughout. The allometric analysis was completed separately for males and females: prepubescents (66 males, 35 females) and pubescents (35 males, 31 females).

Allometric analysis requires an initial examination of the log-log plots to insure rectilinearity. The log of each of the five fatfolds was plotted against the log of fat mass. Also, plots were made for each gender without regard for pubertal status. The studentized residuals of each model were examined with box-and-wisker plots. Leverages greater than 0.05 for the males and 0.04 for the females and Cook's distances greater than 0.7 were employed to examine the aptness of each gender and puberty model (Kleinbaum et al., 1988). All the plots were linear and demonstrated monophasic allometry.

Alphas between the maturational groups were compared by employing dummy variables in the regression analysis (Kleinbaum et al., 1988). Alphas between the fatfolds within each maturational level were com- 
TABLE 2. Allometric coefficients for prepubescent and pubescent male and female fatfolds*

\begin{tabular}{|c|c|c|c|c|c|c|c|c|}
\hline & \multicolumn{4}{|c|}{ Males } & \multicolumn{4}{|c|}{ Females } \\
\hline & \multicolumn{2}{|c|}{ Prepubescent } & \multicolumn{2}{|c|}{ Pubescent } & \multicolumn{2}{|c|}{ Prepubescent } & \multicolumn{2}{|c|}{ Pubescent } \\
\hline & I rog b & Alpha & $\mathrm{Iog} \mathbf{b}$ & Alpha & Log b & Alpha & $\mathrm{Iog} b$ & Alpha \\
\hline Triceps & 0.341 & 0.762 & 0.092 & $0.919^{b}$ & 0.354 & 0.771 & 0.318 & $0.787^{\mathrm{b}}$ \\
\hline Subscapular & -0.201 & $1.118^{\mathrm{a}}$ & -0.006 & $0.941^{a}$ & -0.341 & $1.254^{a}$ & -0.177 & $1.092^{\mathrm{a}}$ \\
\hline Suprailiac & -0.205 & $1.262^{\mathrm{ab}}$ & -0.011 & $1.068^{\mathrm{a}}$ & -0.219 & $1.212^{\mathrm{ab}}$ & 0.015 & $1.019^{a}$ \\
\hline Abdominal & -0.219 & $1.246^{\mathrm{a}}$ & 0.059 & $1.002^{\mathrm{a}}$ & -0.247 & $1.258^{\mathrm{a}}$ & -0.020 & $1.029^{\mathrm{a}}$ \\
\hline Thigh & 0.380 & 0.828 & 0.175 & $0.906^{b}$ & 0.407 & 0.815 & 0.379 & $0.828^{b}$ \\
\hline
\end{tabular}

*All alphas are significantly $(P<.05)$ greater than 0.33 .

Alphas within gender are significantly different $(P<.05)$ between maturation levels.

bAlphas between genders are significantly different $(P<.05)$ within maturation levels.

pared using multivariate analysis of covariance (Wilkinson, 1987).

\section{RESULTS}

The pubescent males were the tallest group, followed by the pubescent females and then the prepubescent children (Table 1). The BM of the pubescents was greater than the prepubescents. No significant differences were found between the groups for fat mass. The order of fat free mass was the same as stature. Percentage body fat was highest for females followed by the prepubescent males and pubescent males. Body fat percentages ranged from 10.4 to $53.3 \%, 9.7$ to $46.8 \%, 8.7$ to $53.3 \%$, and 15.1 to $53.1 \%$ for prepubescent males, prepubescent females, pubescent males, and pubescent females, respectively. The average body fat percentage of all the adolescents was $26.2 \%$.

Table 2 presents the allometric analysis by gender and pubertal status. Alpha is the allometric coefficient (slope of the regression line) and $\log b$ is the $y$ intercept. All alpha coefficients for males and females were significantly $(P<.05)$ greater than 0.33 . Therefore, all skinfolds exhibited positive allometry. Comparisons were made between males and females of the same pubertal status and between pubertal status groups within each gender. It is interesting that irrespective of gender, the subscapular, suprailiac, and abdominal alphas for pubescents were less $(P<.05)$ than the prepubescent alphas. Also, the subscapular, suprailiac, and abdominal log bs for male pubescents were greater $(P<.05)$ than those for male prepubescents. The triceps and thigh log bs for male pubescents were less $(P<.05)$ than those for male prepubes-
TABLE 3. Allometric coefficients for male and female fatfolds $(n=167)^{*}$

\begin{tabular}{lrrrrr}
\hline & \multicolumn{2}{c}{ Males } & & \multicolumn{2}{c}{ Females } \\
\cline { 2 - 3 } \cline { 6 - 6 } & Log $\mathbf{b}$ & Alpha & & Log $\mathbf{b}$ & Alpha \\
\hline Triceps & 0.255 & 0.817 & & 0.338 & 0.778 \\
Subscapular & -0.125 & 1.048 & & -0.269 & 1.182 \\
Suprailiac & -0.127 & 1.183 & & -0.116 & 1.127 \\
Abdominal & -0.112 & 1.150 & & -0.147 & 1.156 \\
Thigh & 0.317 & 0.848 & & 0.395 & 0.820 \\
\hline
\end{tabular}

*No significant differences $(P>.05)$ were found for $\log b$ or alpha between males and females.

cents. Although the same pattern of changes in $\log \mathbf{b}$ was evident for females, only the suprailiac change was significant $(P<.05)$. These changes in $\log b$ are likely the result of small but nonsignificant differences in mean fatfold thicknesses (Table 1).

Few gender differences were found within pubertal groups. 'The prepubescent male suprailiac alpha was greater $(P<.05)$ than the female suprailiac alpha. The pubescent male triceps and thigh alphas were greater $(P<.05)$ than the respective female alphas. No other gender differences $(P>.05)$ were found for the prepubescents or pubescents.

The prepubescent and pubescent data were combined and the allometric analysis of males and females is presented in Table 3. The males and females had similar $(\boldsymbol{P}>.05)$ alphas for each fatfold. The largest alphas and smallest log bs were found for the trunk fatfolds of both the males and females.

Also of interest are the preferential sites of fat deposition with increasing body fatness. Comparisons among fatfolds revealed a similar pattern for prepubescent males and females. Although the triceps and thigh alphas were not different $(P>.05)$, and the subscapular, suprailiac, and abdominal alphas were not different $(P>.05)$, the tri- 
ceps and thigh alphas were significantly $(P<.05)$ less than the subscapular, suprailiac, and abdominal alphas. For pubescent males, no significant differences $(P>.05)$ were found between the alphas. The thigh alpha for pubescent females was not significantly $(P>.05)$ different from the triceps or the subscapular, suprailiac, and abdominal alphas, but, the triceps alpha was less $(P<.05)$ than the subscapular, suprailiac, and abdominal alphas. The latter three alphas were not significantly different from each other $(P>.05)$. The combined data revealed that for males, the triceps and thigh alphas, the subscapular and abdominal alphas, as well as the abdominal and suprailiac alphas were not significantly different $(P>.05)$. In contrast, the female alphas fell into two groups: the triceps and thigh compared to the subscapular, suprailiac, and abdominal.

\section{DISCUSSION}

Allometric analysis revealed a linear loglog relationship between fatfold thickness and the body fat mass of prepubescent and pubescent males and females. The alpha coefficients for both males and females exhibited positive allometry and were greater than 0.33 for all the fatfolds.

These results agree with other studies employing multivariate analysis techniques (Ramirez and Mueller, 1980; Deutsch et al., 1985; Hattori et al., 1987). The advantage of allometric analysis is the site specific alpha coefficients which relate subcutaneous fat to total body fatness. The alpha coefficients reveal the specific sites for increased fat deposition. The male fatfold sites which demonstrated the greatest increase with increased body fat were the suprailiac and abdominal. Alternatively, all three female trunk sites increased at approximately the same rate. Therefore, with increased adiposity the trunk had the greatest fat deposition for both males and females, but the specific location of fat deposition on the trunk was gender specific.

Further, prepubescent males and females had the same pattern of alphas. This pattern contrasted extremity fatfolds with trunk fatfolds. The lack of gender differences is in agreement with Deutsch et al. (1985) and suggests a nongender specific pattern of fat deposition during prepubescence. In contrast, pubescent males and females had no differences between the alphas, except for the female triceps. This homogeneity of alphas is the result of a reduction in trunk alphas without changes in the extremity. Thus, there appears to be a reduction of the importance of the trunk fatfolds to increased adiposity from prepubescence to pubescence.

Malina and Bouchard (1988) also examined the pattern of subcutaneous fat deposition during adolescence. Prepubescent females in Malina and Bouchard (1988) and the present study demonstrated a predominance of the trunk for the deposition of subcutaneous fat. Pubescent females had a more general pattern of fat deposition. The alphas were similar for all fatfolds. Prepubescent males in both studies exhibited the same predominant trunk subcutaneous fat deposition as prepubescent females. Pubescent males of the present study exhibited a decrease in the importance of trunk subcutaneous fat deposition to increased adiposity and no change in the extremity. Malina and Bouchard (1988) demonstrated a maintenance of the trunk as the preeminent site of subcutaneous fat deposition with decreases in the importance of the extremities. It is difficult to reconcile these differences but it is important to recognize a major difference between the studies. The mean fat mass of the pubescent males for the present study was $13.1 \mathrm{~kg}$. In contrast, the mean fat mass of the 13-14-year-old males was approximately $5 \mathrm{~kg}$ for Malina and Bouchard (1988). It is unknown how these differences might effect the results.

The expected alpha coefficient of a onedimensional variable such as fatfold thickness and a three-dimensional variable such as fat mass is 0.33 . It is striking that in the present data all the fatfolds have alphas greater than 0.33 and some were greater than 1.00. Since fatfolds are an estimate of subcutaneous fat, our data show that as total body fat increased, a greater proportion of fat was deposited subcutaneously. It follows that the subcutaneous fat of an obese adolescent would be a greater proportion of total body fat than for a lean adolescent. These results are in partial agreement with CT scanning data of adults (Grauer et al., 1984), in whom it was shown that as total fatness increased, females deposited more fat subcutaneously, while males deposited more fat internally. The present study also agrees with the cadaver data of Martin (1984). In both males and females, as the total adipose tissue mass increased, exter- 
nal adipose tissue mass increased faster than internal adipose tissue mass.

In conclusion, allometric analysis has confirmed that the trunk is the primary site of increased subcutaneous fatness in prepubescent males and females. Furthermore, pubescent males and females appear to deposit subcutaneous fat equally in both the trunk and extremity.

\section{ACKNOWLEDGMENTS}

Supported in part by NIH-AM/HD 30989 and NIH-AM/HD 26351. Our appreciation is expressed to Richard A. Boileau and Mary H. Slaughter from the Physical Fitness Research Laboratory at the University of Illinois at Urbana-Champaign and Timothy G. Lohman from the University of Arizona for use of their data and participation in the project.

\section{LITERATURE CITED}

Akers R, Buskirk ER (1969) An underwater weighing system utilizing "Force Cube" transducers. J. Appl. Physiol. 26:649-652, 1969.

Ashwell M, Chinn S, Stalley S, Garrow JS (1978) Female fat distribution-a photographic and cellularity study. Int. J. Obesity 2:289-302.

Ashwell M. Chinn S, Stalley S, Garrow JS (1982) Female fat distribution-a simple classification based on two circumference measurements. Int. J. Obesity $6: 143-152$.

Becque MD, Hattori K, Katch VL, Rocchini AP (1986) Relationship of fat patterning to coronary artery disease risk in obese adolescents. Am. J, Phys. Anthropol. 71:423-429.

Behnke AR, Wilmore JH (1974) Evaluation and Regulation of Body Build and Body Composition. Englewood Cliffs, New Jersey: Prentice-Hall.

Bjorntorp P (1985) Regional patterns of fat distribution. Ann. Int. Med. 103:994 995.

Boileau RA, Wilmore JH, Lohman TG, Slaughter MH, Riner WF (1981) Estimation of body density from skinfold thicknesses, body circumferences and skeletal widths in boys aged 8 to 11 years: comparison of two samples. Hum. Biol. 53:575-592.

Deutsch MI, Mueller WH, Malina RM (1985) Androgyny in fat patterning is associated with obesity in adolescents and young adults. Ann. Hum. Biol. 12:275-286.

Forbes GB, Amirhakimi GH (1970) Skinfold thickness and body fat in children. Hum. Biol. 42:401-418.

Frisancho AR, Flegal PN (1982) Advanced maturation associated with centripetal fat pattern. Hum. Biol. 54:717-727.

Garn SM, Harper RV (1955) Fat accumulation and weight gain in the adult male. Hum. Biol. 27:39-49.

Grauer WO, Moss AA, Gann CE, Goldberg HI (1984) Quantification of body fat distribution in the abdomen using computed tomography. Am. J. Clin. Nutr. 39:631-637.

Hattori K, Becque MD, Katch VL, Rocchini AP, Boileau $\mathrm{R}$, Slaughter $\mathrm{MH}$, Lohman TG (1987) Fat patterning of adolescents. Ann. Hum. Biol. 14:23-28.

Huxley JS, Tessier G (1936) Terminology of relative growth. Nature 137:780-781.

Katch FI (1959) Practice curves and errors of measurement in estimating underwater weight by hydrostatic weighing. Med. Sci. Sports 1:212-216.

Klienbaum DG, Kupper LL, Muller KE (1988) Applied Regression Analysis and Other Multivariate Methods. Boston: PWS-Kent Publishing Company.

Malina RM, Bouchard C (1988) Subeutaneous fat distribution during growth. In $\mathrm{C}$ Bouchard and FE Johnston (eds.): Fat Distribution During Growth and Later Health Outcomes. New York: Alan R. Liss, pp. 63-84.

Martin AD (1984) An anatomical basis for assessing human body composition: Evidence from 25 dissections. Simon Fraser University: Doctoral Dissertation.

Mueller WH, Wollheb JC (1981) Anatomical distribution of subcutaneous fat and its description by multivariate method: How valid are principal components? Am. J. Phys. Anthropol. 54:25-34.

Ramirez ME, Mueller WH (1980) The development of obesity and fat patterning in Tokelau children. Hum. Biol. 52:675-687.

Robson JRK, Bazin M, Soders R (1971) Ethnic differences in skinfold thickness. Am. J. Clin. Nutr. 24:864 868.

Scholl D (1950) The theory of differential growth analysis. Proc. Roy. Soc. Lon. [Biol] 137:470-474.

Siri WE (1961) Body composition from fluid spaces and density: Analysis of methods. In J Brožek and A Henschel (eds.): Techniques for Measuring Body Composition. Washington, DC: National Academy of Sciences-National Research Council, pp 223-244.

Tanner JM (1962) Growth at Adolescence, 2nd ed. Oxford: Blackwell Scientific Publications. 